\title{
The Stomach-Derived Hormone Ghrelin Increases Impulsive Behavior
}

\author{
Rozita H Anderberg', Caroline Hansson',2, Maya Fenander', Jennifer E Richard', Suzanne L Dickson ${ }^{3}$, \\ Hans Nissbrandt ${ }^{4}$, Filip Bergquist ${ }^{4}$ and Karolina P Skibicka*,I \\ 'Department of Physiology/Metabolic Physiology, Institute of Neuroscience and Physiology, The Sahlgrenska Academy at the University of \\ Gothenburg, Gothenburg, Sweden; '2Department of Molecular and Clinical Medicine, Institute of Medicine, The Sahlgrenska Academy at the \\ University of Gothenburg, Gothenburg, Sweden; ${ }^{3}$ Department of Physiology/Endocrinology, Institute of Neuroscience and Physiology, The \\ Sahlgrenska Academy at the University of Gothenburg, Gothenburg, Sweden; ${ }^{4}$ Department of Pharmacology, Institute of Neuroscience and \\ Physiology, The Sahlgrenska Academy at the University of Gothenburg, Gothenburg, Sweden
}

Impulsivity, defined as impaired decision making, is associated with many psychiatric and behavioral disorders, such as attention-deficit/ hyperactivity disorder as well as eating disorders. Recent data indicate that there is a strong positive correlation between food reward behavior and impulsivity, but the mechanisms behind this relationship remain unknown. Here we hypothesize that ghrelin, an orexigenic hormone produced by the stomach and known to increase food reward behavior, also increases impulsivity. In order to assess the impact of ghrelin on impulsivity, rats were trained in three complementary tests of impulsive behavior and choice: differential reinforcement of low rate (DRL), go/no-go, and delay discounting. Ghrelin injection into the lateral ventricle increased impulsive behavior, as indicated by reduced efficiency of performance in the DRL test, and increased lever pressing during the no-go periods of the go/no-go test. Central ghrelin stimulation also increased impulsive choice, as evidenced by the reduced choice for large rewards when delivered with a delay in the delay discounting test. In order to determine whether signaling at the central ghrelin receptors is necessary for maintenance of normal levels of impulsive behavior, DRL performance was assessed following ghrelin receptor blockade with central infusion of a ghrelin receptor antagonist. Central ghrelin receptor blockade reduced impulsive behavior, as reflected by increased efficiency of performance in the DRL task. To further investigate the neurobiological substrate underlying the impulsivity effect of ghrelin, we microinjected ghrelin into the ventral tegmental area, an area harboring dopaminergic cell bodies. Ghrelin receptor stimulation within the VTA was sufficient to increase impulsive behavior. We further evaluated the impact of ghrelin on dopamine-related gene expression and dopamine turnover in brain areas key in impulsive behavior control. This study provides the first demonstration that the stomach-produced hormone ghrelin increases impulsivity and also indicates that ghrelin can change two major components of impulsivity - motor and choice impulsivity.

Neuropsychopharmacology (2016) 4I, I199-1209; doi:I0.1038/npp.2015.297; published online 2I October 2015

\section{INTRODUCTION}

Impulsivity, defined as impaired decision making or action without foresight, is associated with many psychiatric and behavioral disorders such as attention-deficit/hyperactivity disorder, substance abuse, and eating disorders (Dawe and Loxton, 2004; Schag et al, 2013). Much remains to be discovered about the neurobiological mechanisms that govern impulsivity. Understanding factors that induce impulsive behavior can provide new therapeutic avenues for many impulsivity-associated psychiatric disorders. Major neurotransmitters, such as dopamine and serotonin, have

*Correspondence: Dr KP Skibicka, Department of Physiology/Metabolic Physiology, Institute of Neuroscience and Physiology, The Sahlgrenska Academy at the University of Gothenburg, Medicinaregatan I I, PO Box 434, Gothenburg SE-405 30, Sweden, Tel: +46 31786 3436, Fax: +46 31 786 35 I2, E-mail: Karolina.Skibicka@neuro.gu.se

Received 6 February 2015; revised 12 September 2015; accepted 15 September 2015; accepted article preview online I October 2015 been implicated in regulating impulsive behavior (Bizot et al, 1999; Eagle et al, 2009). Reduced dorsal striatal dopamine signaling at the dopamine 1 receptor (D1R) reduces impulsivity and at the dopamine 2 receptor (D2R) increases impulsivity (Eagle et al, 2011). Reduced central serotonin signaling increases impulsive action and choice in rats and pharmacological and optogenetic activation of dorsal raphe serotonin neurons reduces choice impulsivity (Harrison et al, 1997; Miyazaki et al, 2012, 2014). Interestingly both dopamine and serotonin are modulated by a stomachproduced hormone-ghrelin (Abizaid et al, 2006; Skibicka et al, 2013; Hansson et al, 2014)-however, the impact of ghrelin on impulsivity remains unexplored.

Ghrelin, a hormone produced in the stomach, is primarily recognized for its orexigenic role. Ghrelin levels increase before each meal that subsequently leads to the food intake (Cummings et al, 2004). The orexigenic action of ghrelin is primarily mediated by the growth hormone secretagogue receptors (GHSR) in the central nervous system. But ghrelin's actions in the brain are not limited to control of 
basic food intake; ghrelin also increases reward behavior for food, alcohol, and other substances of abuse (Jerlhag et al, 2009; Skibicka et al, 2011a; Menzies et al, 2013). The impact of ghrelin on reward is thought to be mediated by dopamine and opioid signaling (Skibicka and Dickson, 2011, Skibicka et al, 2012, 2013). Food reward behavior has recently been shown to positively correlate with impulsivity (Velazquez-Sanchez et al, 2014). The impact of ghrelin on neurotransmitters critical for regulation of impulsive behavior, taken together with the regulatory role for ghrelin on food reward behavior (a behavior that correlates with impulsivity), led us to hypothesize that ghrelin's neurobiological role could extend to the regulation of impulsivity.

Impulsivity is a heterogeneous construct and in its simplest form can be deconstructed into two components: impulsive action (motor disinhibition) and impulsive choice (impulsive decision making). In order to assess the role of ghrelin in impulsivity, three complementary rodent tests were used: differential reinforcement of low rate (DRL), go/no-go, and delay discounting. All three tests measure the ability to inhibit a behavioral response. While DRL and go/no-go measure impulsive action (the ability to restrain a response), delay discounting measures impulsive choice (the ability to defer gratification) (Bari and Robbins, 2013). The application of different tests in the current study allowed us to assess different aspects of impulsivity after ghrelin or a GHSR antagonist was infused into the lateral ventricle (LV). In order to further understand the neuroanatomical substrate underlying ghrelin's impact on impulsivity, measured in the DRL task, ghrelin was also directly microinjected into the ventral tegmental area (VTA), an area harboring dopaminergic cell bodies of neurons projecting to, for example, the nucleus accumbens (NAc) and the orbitofrontal cortex (OFC). Finally, we measured dopamine turnover and the expression of genes previously associated with impulsivity in four brain nuclei strongly implicated in impulsivity control-the OFC, the dorsal striatum, the medial prefrontal cortex (mPFC), and the NAc (Bari and Robbins, 2013; Jupp et al, 2013).

\section{MATERIALS AND METHODS}

\section{Animals}

Adult male Sprague-Dawley rats, weighing 200-250 g (Charles River, Germany) were housed in individual plastic cages under 12/12-h dark/light cycle, at $20^{\circ} \mathrm{C}$ and $50 \%$ humidity. Standard chow (Harlan Tekland; Norfolk, England) and water were available ad libitum unless otherwise indicated. The University of Göteborg Institutional Animal Care and Use Committee guidelines approved all experiments (ethical permission 195-13).

\section{Drugs}

Ghrelin and angiotensin II were purchased from Tocris (Bristol, UK). JMV2959, a ghrelin receptor antagonist, was obtained from Aeterna Zentaris $\mathrm{GmbH}$ (Frankfurt, Germany) (Moulin et al, 2007). All drugs were dissolved in artificial cerebrospinal fluid (aCSF), vehicle for central injections. Ghrelin and angiotensin were stored as aliquots in $-20^{\circ} \mathrm{C}$; JMV2959 was dissolved immediately before injections.

\section{Brain Cannulation}

For behavioral testing, all rats were implanted with a guide cannula (26-gauge cannula; Plastics One, Roanoke, VA) targeting the left or right LV or the VTA under ketamine/ xylazine anesthesia. The cannulas were positioned and attached to the skull with dental acrylic and jeweller's screws and closed with an obturator (Skibicka et al, 2011a). For detailed information, see Supplementary Information.

\section{Behavioral Testing}

Three complementary tests were used to examine impulsive behavior, each done in a separate group of rats. Testing occurred in eight operant-conditioning chambers (Med Associates; St Albans, VT, USA) equipped with a house light, two retractable levers located on either side of a centrally positioned receptacle into which a dispenser delivered $45 \mathrm{mg}$ sucrose food pellets (TestDiet; Purina). In experiment 3, movement was detected by infrared photodiodes. The apparatus was controlled using software written in-house by Karolina Skibicka (for the DRL and go/no-go tests) and external consultant (Søren Ellegaard) (for the delay discounting test).

\section{Differential Reinforcement of Low Rate}

DRL schedules are used to maintain a low rate of responding because a reinforcer is provided only when a response is made after a specified, predetermined time interval (here $20 \mathrm{~s}$ ) has elapsed. The DRL procedure was modified from Peterson et al (2003). Impulsivity, or the inability to withhold a response, was assessed by the efficiency of the performance-that is the ratio between the responses rewarded with a food pellet and total responses (rewarded +incorrect). Higher efficiency reflects a more accurate and less impulsive performance. Rats were first trained on a fixed ratio 1 schedule and then progressed through FR3, then DRL 5, and finishing at DRL 20. For details, see Supplementary Information. The use of the efficiency parameter as a reflection of impulsivity behavior and a shorter interval of the DRL was based on previous literature, for example, Velazquez-Sanchez et al (2014).

In order to determine the impact of central ghrelin on DRL performance, rats $(n=9)$ were injected with ghrelin $(1 \mu \mathrm{g}$ or $2 \mu \mathrm{g} / 1 \mu \mathrm{l})$ or vehicle (aCSF, $1 \mu \mathrm{l})$ into the LV. The DRL test was performed $20 \mathrm{~min}$ after injections. In order to assess whether ghrelin receptor stimulation directly in the VTA is sufficient to change impulsive behavior, rats $(n=7)$ were unilaterally microinjected with ghrelin $(0.05 \mu \mathrm{g} / 0.5 \mu \mathrm{l})$ or vehicle $(0.5 \mu \mathrm{l}$ of aCSF). Next we assessed whether signaling at the central ghrelin receptor was necessary for impulsive behavior as measured by DRL. To ensure high circulating levels of endogenous ghrelin, all rats were mildly food deprived before each injection day ( $10 \mathrm{~g}$ of chow overnight, which represented $50 \%$ of overnight intake). Rats $(n=10)$ were injected with JMV2959, a ghrelin receptor antagonist, or vehicle into the LV. For all experiments, injections were performed in a Latin square design, 
counterbalanced, where each rat received each condition over different injection days, with at least $48 \mathrm{~h}$ separating each injection day.

\section{Go/No-Go}

The go/no-go procedure was modified from Masaki et al (2006). Rats were first trained to press either the left or the right lever to obtain one food pellet (session-performance criteria of 60 rewarded trials, 30 per lever). Both visual (stimulus light) and auditory (tone) cues were used to signal go or no-go periods; both signals were present during the entire period. The go periods were signaled by a light stimulus placed above the active lever (which was on during the go period). The no-go period was signaled by a tone; the stimulus light was off during the no-go periods. The transition phase between the go and no-go periods was signaled by a brief flash of the house light. Each test session consisted of 90 trials, with an equal number of go and no-go trials presented alternately. Each trial consisted of 15-, 30-, and 45-s periods in random order. A food pellet was supplied on a variable ratio 6 (VR-6) when the rat pressed the active lever during go trials, while no pellet was supplied when the rat pressed the active lever during no-go trials; the rat therefore lost an opportunity to receive a food pellet by pressing the active lever during the no-go period. The pellet for the no-go trials was delivered at the end of each trial if the rat did not press the lever during the trial. For the go trials, the pellet was delivered after pressing the lever on a VR-6 ratio. One of the two levers was inactive (pressing on that lever had no consequences) and served as a general activity/arousal control. The other lever was designated as the active lever. Both levers were extended for the entire duration of each trial. The criterion for learning was $75 \%$ correct response ratio. A test session ( $45 \mathrm{~min}$ ) was conducted once a day. Most rats achieved the criterion in $<20$ go/no-go sessions. Rewards earned during go and no-go trials, active lever presses during go and no-go trials and inactive lever presses were recorded by the software and analyzed. Increased impulsivity is defined as the inability to restrain from lever pressing during the no-go periods.

In order to determine the impact of central ghrelin on the go/no-go test performance, rats $(n=9)$ were injected with ghrelin $(1 \mu \mathrm{g}$ or $2 \mu \mathrm{g} / 1 \mu \mathrm{l})$ or vehicle (aCSF, $1 \mu \mathrm{l})$ into the LV. Go/no-go test was performed $20 \mathrm{~min}$ after injections.

\section{Delay Discounting}

The delay discounting procedure was modified from Mar and Robbins (2007). Rats were first trained to press either the left or right lever to obtain one food pellet (session-performance criteria of 60 rewarded trials (30 per lever)). Rats were then trained on the delay discounting procedure. Each rat had one lever designated as immediate (associated with one, immediate pellet) and one lever as delay (associated with four food pellets, delivered after a delay that was increased progressively $(0,10,20,40 \mathrm{~s})$ between successive blocks). Impulsive choice in this test is defined as an inability to delay gratification, thus choosing the immediate but smaller reward over the large reward delivered with a delay.
In order to determine the impact of central ghrelin on the delay discounting performance rats $(n=26)$ were injected with ghrelin $(1 \mu \mathrm{g} / 1 \mu \mathrm{l})$ or vehicle (aCSF, $1 \mu \mathrm{l})$ into the LV and placed in the operant box for the delay discounting test $20 \mathrm{~min}$ later. Horizontal plane locomotor activity was measured during the delay discounting test with 10 evenly distributed infrared detectors. To control for potential impact of hunger level, as well as early trial-induced satiety, two additional delay discounting experiments were performed. In the first control experiment, rats were tested under 50 or $70 \%$ overnight chow level. The second experiment was a mock delay discounting task, where rats were trained in a manner identical to that used for the delay discounting task (the trial structure was identical to that used here for the delay discounting task), except no delay was ever imposed on the large reward.

\section{Gene Expression}

Ninety minutes after the ghrelin injection (intra-LV; $2 \mu \mathrm{g} / 1 \mu \mathrm{l})$, the brains were rapidly removed and the NAc, dorsal striatum, $\mathrm{mPFC}$, and $\mathrm{OFC}$ were dissected using a brain matrix, frozen in liquid nitrogen, and stored at $-80^{\circ} \mathrm{C}$ for later determination of mRNA expression. Gene expression values were calculated based on the $\Delta \Delta \mathrm{Ct}$ method (Livak and Schmittgen 2001), where the vehicle-treated group was designated the calibrator. A combination of $\beta$-actin and peptidylprolyl isomerase A was used as reference genes for the OFC. $\beta$-Actin was used as the reference gene for the NAc, dorsal striatum, and mPFC.

\section{Dopamine Turnover}

Impact of acute central ghrelin on dopamine turnover in the OFC, NAc, and dorsal striatum were determined via HPLC. Ninety minutes after ghrelin infusion (intra-LV; $2 \mu \mathrm{g} / 1 \mu \mathrm{l}$ ), rats were decapitated, and the brains were rapidly removed. The OFC, NAc, and dorsal striatum were dissected using a brain matrix. Dissected brain areas were frozen and stored at $-80^{\circ} \mathrm{C}$, later dopamine and its metabolite were determined via HPLC as described previously (Anderberg et al, 2014). The levels of dopamine metabolites in the OFC were below the detection threshold in all samples, thus dopamine turnover in the OFC was not determined.

\section{RESULTS}

\section{Central Ghrelin Signaling is Necessary and Sufficient for Impulsivity Control in the DRL Test}

Ghrelin treatment increased impulsive behavior as there was a significant effect of drug treatment $\left(\mathrm{F}_{(2,16)}=4.4, p<0.05\right)$ on the efficiency of responses, and post-hoc tests indicated that the higher dose of ghrelin significantly reduced the efficiency of performance in the DRL test (Figure 1c). Vehicle-injected rats were within a similar efficiency range as those detected previously for rats in the DRL task, though they perhaps resembled the lower impulsivity animals more (Velazquez-Sanchez et al, 2014). The ghrelin-induced reduced efficiency in the DRL performance was not associated with changes in rewards earned $\left(\mathrm{F}_{(2,16)}=1.2\right.$; $p=0.3)$ or active lever presses $\left(\mathrm{F}_{(2,16)}=2.68 ; p=0.1\right)$, 

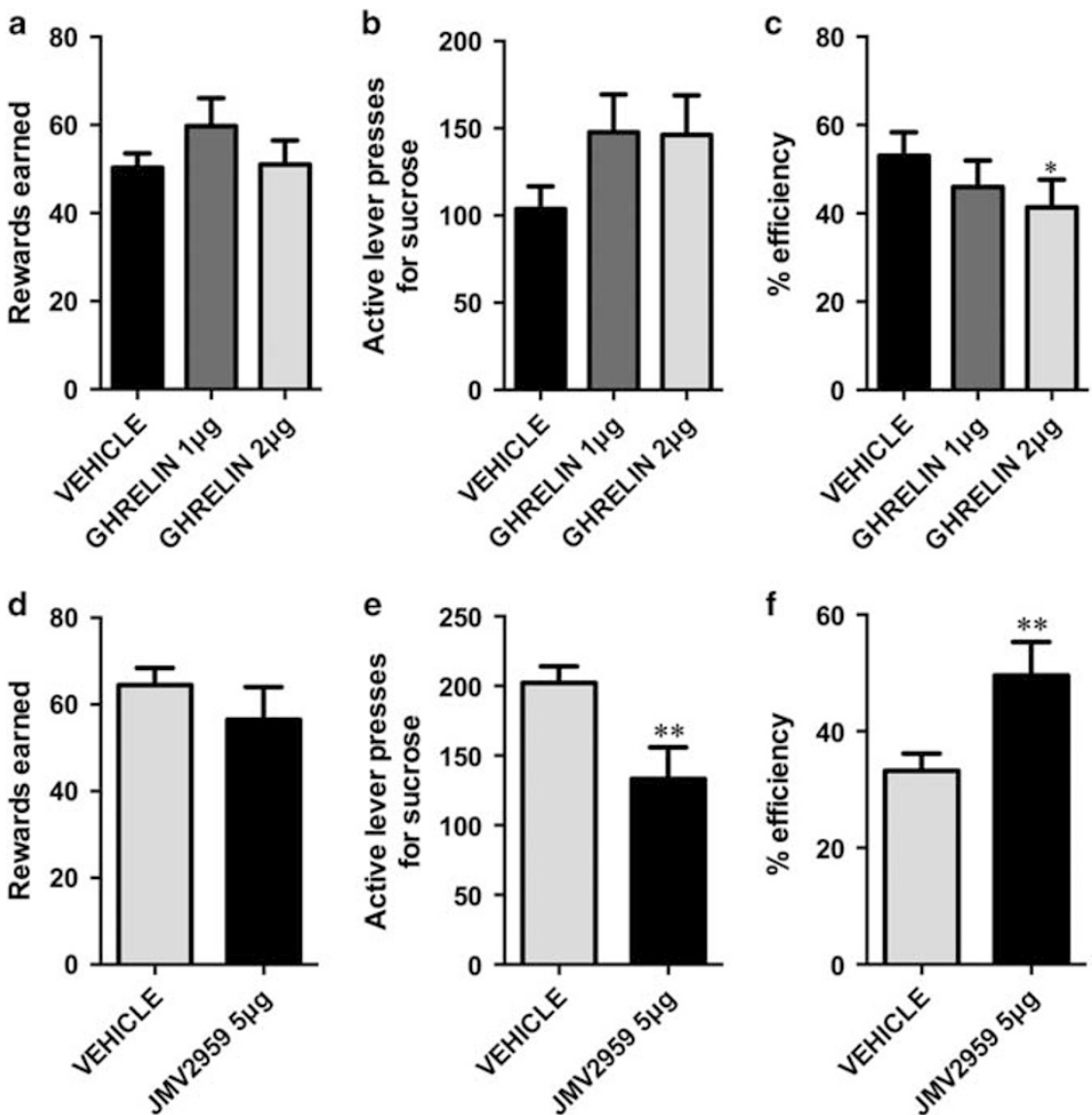

Figure I Ghrelin is necessary and sufficient to increase impulsive action measured in the DRL task. Impulsive action, defined as the inability to withhold a response, was assessed on the DRL 20-s schedule. Centrally injected ghrelin did not significantly alter the rewards earned in the DRL task (a) or the number of responses on the active lever (b); however, it significantly reduced the efficiency of the performance (c). Centrally injected GHSR antagonist, JMV2959, did not significantly alter the rewards earned in the DRL task (d); however, it significantly reduced the amount of active lever presses emitted to obtain the rewards (e), and it significantly increased the efficiency of the performance in the task ( $f$ ). Efficiency was defined as the ratio between the rewarded responses and the total (rewarded+incorrect) responses. Data are expressed as mean \pm SEM. $n=9-10$ per each treatment group. $* p<0.05, * * 2<0.005$.

indicating that the ghrelin-treated rats emitted more lever presses prematurely (Figure 1a and b). Conversely, blockade of central ghrelin receptors significantly reduced impulsive behavior as indicated by a $50 \%$ increase in efficiency of the performance in the DRL task after ghrelin antagonist injection $(t=4.13 ; p<0.005$; Figure 1f). The increased efficiency was not associated with changes in the number of sugar rewards earned $(t=1.23 ; p=1.2$; Figure $1 \mathrm{~d})$. As vehicle-injected rats were not food deprived during the ghrelin injection study, while vehicle-injected rats during the antagonist study were mildly food restricted overnight, a situation in which high circulating endogenous levels of ghrelin are expected (Tschop et al, 2000), an additional comparison can be made between these two groups to assess the effect of food deprivation on the DRL performance. Food deprivation significantly increased impulsive behavior (percentage of efficiency for non-food-restricted rats: $53.06 \pm 5.337, n=9$ and food-restricted rats: $33.22 \pm 2.971$, $n=10 ; t=3.34, p<0.005)$. To investigate the potential neural substrates underlying the impact of ghrelin on impulsivity, we stimulated ghrelin receptors directly in the VTA. The activation of ghrelin receptors in the VTA proved to be sufficient to increase impulsive behavior (reduce the efficiency of performance in the DRL task; $t=4.04$, $p<0.01$ ), without changing the number of rewards earned, $t=0.15, p=9$ (Figure 2).

\section{Central Ghrelin Increases Impulsive Behavior in the Go/No-Go Test}

In go/no-go testing, rats were trained to press a single lever if the go cue was presented (stimulus light) or to refrain from pressing during the no-go cue (tone). One-way ANOVA indicated that ghrelin significantly increased the number of rewards earned $\left(\mathrm{F}_{(2,16)}=5.77, p<0.05\right.$; Figure $\left.3 \mathrm{a}\right)$ and the number of lever presses $\left(\mathrm{F}_{(2,16)}=4.1, p<0.05\right.$; Figure $\left.3 \mathrm{~b}\right)$ during the go period, a result consistent with a large body of literature indicating that ghrelin increases food reward behavior in an operant task (Skibicka and Dickson, 2011). Consistent with the idea that ghrelin increases impulsive behavior, the number of active lever presses during the no go period was also increased by ghrelin $\left(\mathrm{F}_{(2,16)}=4.6, p<0.05\right.$; Figure $3 \mathrm{c}$ ). In contrast, the total number of inactive lever presses $\left(\mathrm{F}_{(2,16)}=0.46, p=0.64\right.$; Figure $\left.3 \mathrm{~d}\right)$, the total number of rewards earned $\left(56 \pm 3.5,57 \pm 5.167 \pm 7.4 ; \mathrm{F}_{(2,16)}=2.8\right.$, $p=0.11$ ), and rewards earned during the no-go periods 

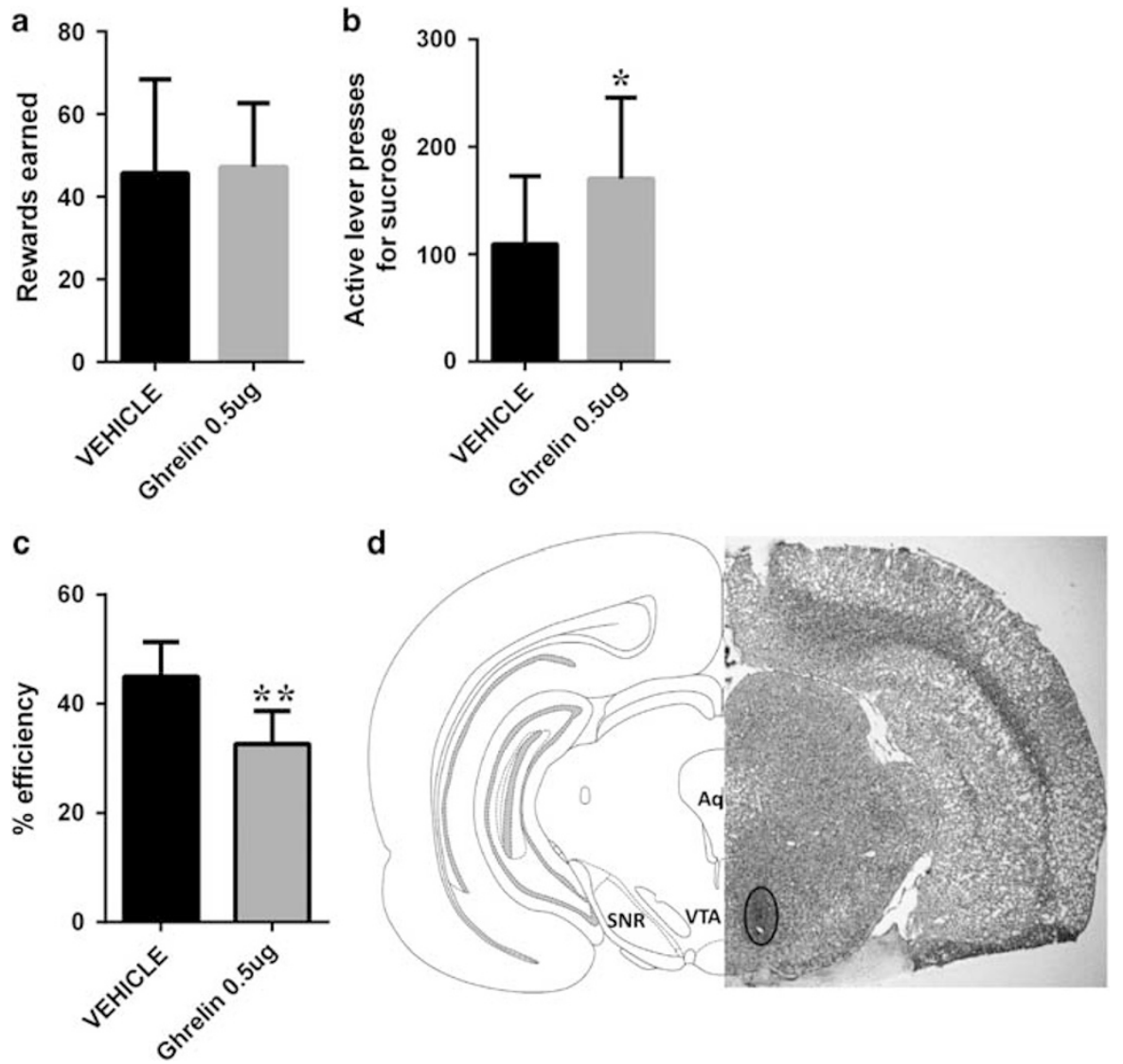

Figure 2 VTA-injected ghrelin increases impulsive action measured in the DRL task. Ghrelin microinjected into the VTA did not significantly alter the rewards earned in the DRL task (a), but it significantly increased the number of responses emitted on the active lever (b) and significantly reduced the efficiency of the performance (c). Photomicrograph of a $40-\mu \mathrm{m}$ coronal section of rat brain illustrating the injection site and schematic representation of the VTA according to the rat brain atlas (d). Data are expressed as mean \pm SEM. $n=7$ per each treatment group. $* p<0.05, * *{ }^{*} p<0.005$.

$\left(\mathrm{F}_{(2,16)}=0.60, p=0.56\right.$; Figure $\left.3 \mathrm{e}\right)$ were not altered by ghrelin.

\section{Ghrelin Increases Impulsivity in the Delay Discounting Test without Changing Locomotor Activity}

Two-way ANOVA (ghrelin $\times$ delay) of the choice data across different delays and drug treatment revealed a significant effect of delay $\left(\mathrm{F}_{(3,75)}=108.6, p<0.0001\right)$ and a trend toward an overall effect of ghrelin $\left(\mathrm{F}_{(1,25)}=3.62, p=0.06\right)$. Moreover, a significant interaction between the delay and ghrelin treatment $\left(\mathrm{F}_{(3,75)}=9.47, p<0.0001\right)$ was detected, implying that the effect of ghrelin differed across different delay periods. Post-hoc pair-wise comparisons confirmed that ghrelin significantly increased the amount of large rewards earned when both large and small rewards were delivered immediately (delay $=0$ ); however, at the 10 - and 20 -s delay ghrelin-treated rats chose the smaller immediate rewards over the large delayed rewards (Sidak's multiple comparisons tests; Figure 4a). The impulsive behavior resulted in a loss of rewards earned during the 10- and 20 -s delays but not when there was no delay imposed on the large rewards. Two-way ANOVA (ghrelin $\times$ delay) revealed: a significant effect of delay on the number of rewards earned during the discounting task $\left(\mathrm{F}_{(3,72)}=114.1, p<0.0001\right)$, no significant effect of ghrelin $\left(\mathrm{F}_{(1,24)}=2.85, p=0.1\right)$, but a significant interaction between ghrelin and delays

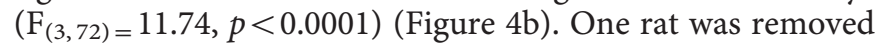
from the analysis owing to erroneously recorded electronic data. Also, importantly, when all rewards earned during all delay periods are summed up, the ghrelin-infused animals earned significantly less rewards $(36.2 \pm 4.7$ vs $25.0 \pm 3.8$ pellets, $p<0.005$, vehicle $v s$ ghrelin, respectively). The total number of pellets earned also tended to be lower for ghrelininjected rats $(60 \pm 4.5$ and $53 \pm 3$ for vehicle- and ghrelininjected rats, respectively; $p=0.1$ ). Ghrelin did not change the latency to press the lever (Supplementary Information, Supplementary Figure S1). Locomotor activity was not altered during the test by the ghrelin treatment $(t=1.02, p=0.3$; Figure $4 \mathrm{c})$. For the delay discounting task, unlike for the DRL, the level of food deprivation did not affect impulsive behavior (Supplementary Figure S2). In a mock delay discounting task, a task with identical trial structure to the delay discounting task, except without any delay ever imposed on the large rewards, ghrelin had no effect on choice of large rewards, the number of reward earned, or latency to press the lever (Supplementary Figure S3A-C). The total number of pellets earned was: $100 \pm 11.9$ and $99 \pm 11.6$ for vehicle- and ghrelin-injected rats, respectively $(p=0.9)$ (see Supplementary Information for 

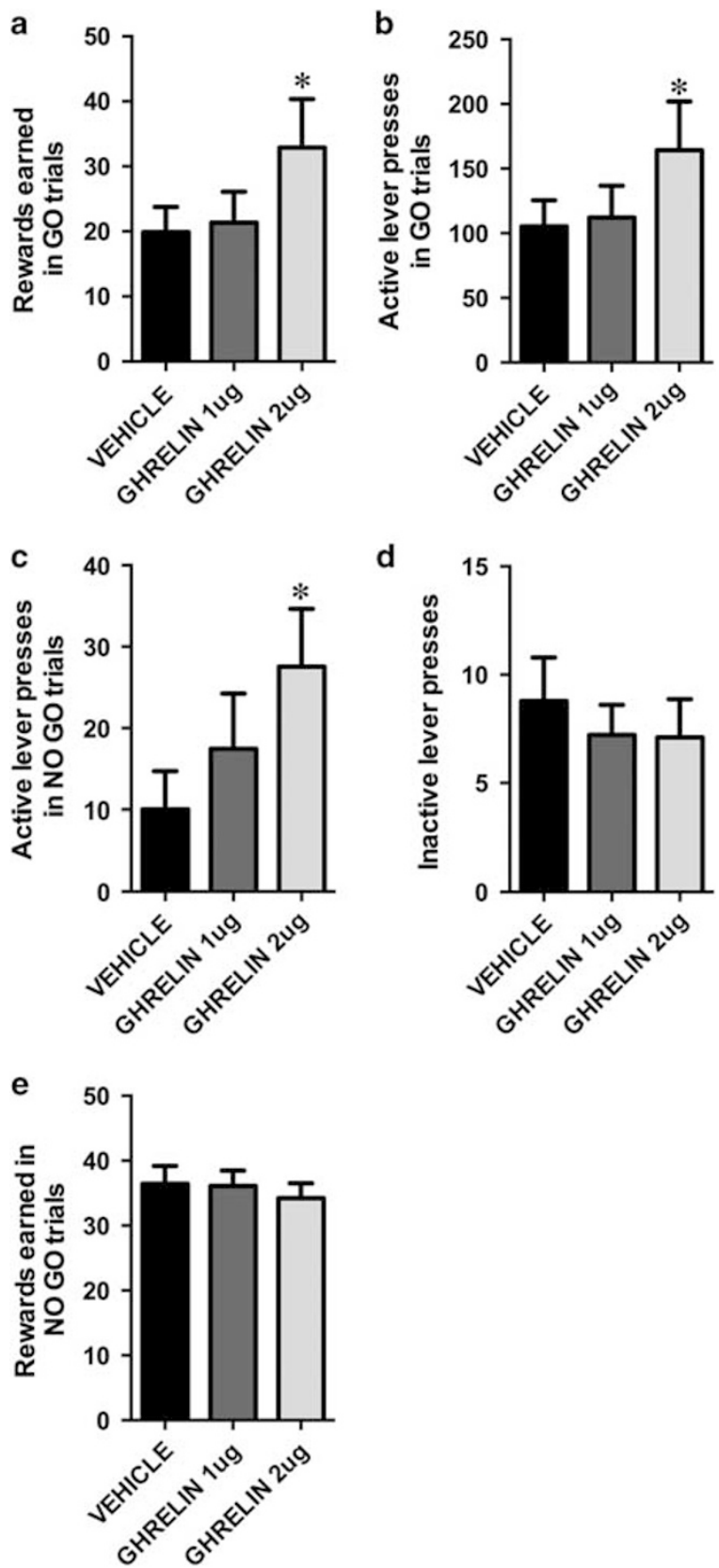

Figure 3 Ghrelin increases impulsive action measured in the go/no-go task. Centrally injected ghrelin increased the number of rewards earned (a) and the number of active lever presses (b) during the go periods of the go/no-go task, indicating that ghrelin increases the motivation to obtain food rewards. However, ghrelin also increased the number of active lever presses during the no-go period (c), potentially indicating an inability to withhold a response despite the no-go cue. Ghrelin had no effect on the number of responses emitted on the inactive lever (d), which supports lack of changes in general motor activity. Number of sucrose pellets earned during the no-go trials (e). Data are expressed as mean \pm SEM. $n=9$ per each treatment group. ${ }^{*} p<0.05$.

further details). These results further demonstrate that the rats were very far from the point of satiation immediately after the mock delay discount task as all rats displayed sufficient hunger to consume significant amount of chow

(Supplementary Figure S3D). Moreover, ghrelin significantly increased the amount of chow eaten, demonstrating that the ghrelin administration was effective.

\section{Gene Expression and Dopamine Turnover}

Ghrelin increased the turnover of dopamine in the NAc and dorsal striatum (Figure $5 \mathrm{a}-\mathrm{d}$ ). The expression of catechol-Omethyltransferase (COMT), DAT, or dopamine receptors was not altered by ghrelin in the NAc or dorsal striatum (Figure $5 \mathrm{e}$ and $\mathrm{f}$ ). In the OFC, the mRNA expression of COMT was decreased in the ghrelin-treated rats relative to vehicle-treated controls $(p<0.05$, Figure $5 \mathrm{~g})$. In the same brain region, the expression of one of the glutamate receptors (Grm2, $p<0.05)$ was reduced (Supplementary Figure S4A), and the expression of neuropeptide Y receptor Y1 (Npylr, $p<0.05)$ was increased in the ghrelin-treated rats relative to vehicle-treated controls (Supplementary Figure S4C). There were no changes in serotonin (Supplementary Figure S4B), opioid (Supplementary Figure S4C), or other dopaminerelated (Figure $5 \mathrm{~g}$ ) genes. In the mPFC the expression of a gene previously associated with impulsivity-like behavior in mice, neuregulin-3 (Loos et al, 2014) was reduced (Figure $5 \mathrm{~h}$ ). In contrast, there were no significant changes in dopamine-related gene expression in this region (Figure 5h).

\section{DISCUSSION}

This study provides the first demonstration that the stomach-produced hormone ghrelin increases impulsivity in rats in three different tasks of impulsive responding. Centrally applied ghrelin (1) increased premature responding in the DRL test, (2) increased responding during the no-go periods of the go/no-go test, and finally (3) reduced the choice of larger but delayed rewards in the delay discounting test. The impact of ghrelin on all three tests not only strengthens the conclusion that ghrelin regulates impulsive responding but also indicates that ghrelin can change two major components of impulsivity-motor and choice impulsivity.

Two impulsivity tests applied here, the DRL and the go/no-go, suggest a necessary and sufficient role for central ghrelin signaling in maintenance of motor impulsivity. Ghrelin increased the amount of premature responses in the DRL task, indicating that ghrelin-injected rats had a reduced capacity to wait the appropriate amount of time (20 s) before pressing a lever to obtain a reward-a task they were significantly more efficient at on the days when they were infused with vehicle instead of ghrelin. A similar reduction in efficiency of responses during a 15-s DRL task was recently reported to be a reflection of impulsivity behavior (Velazquez-Sanchez et al, 2014). Emerging data suggest that sugar abstinence leads to similarly impaired performance in the DRL 20-s task in rats (Mangabeira et al, 2015). Whether increased levels of ghrelin during sugar withdrawal are a contributing factor to this impaired impulsivity is an interesting question for future exploration. Effects of ghrelin on motor impulsivity are also confirmed by the go/no-go test results, where rats injected with ghrelin were nearly three times more likely to act despite the 

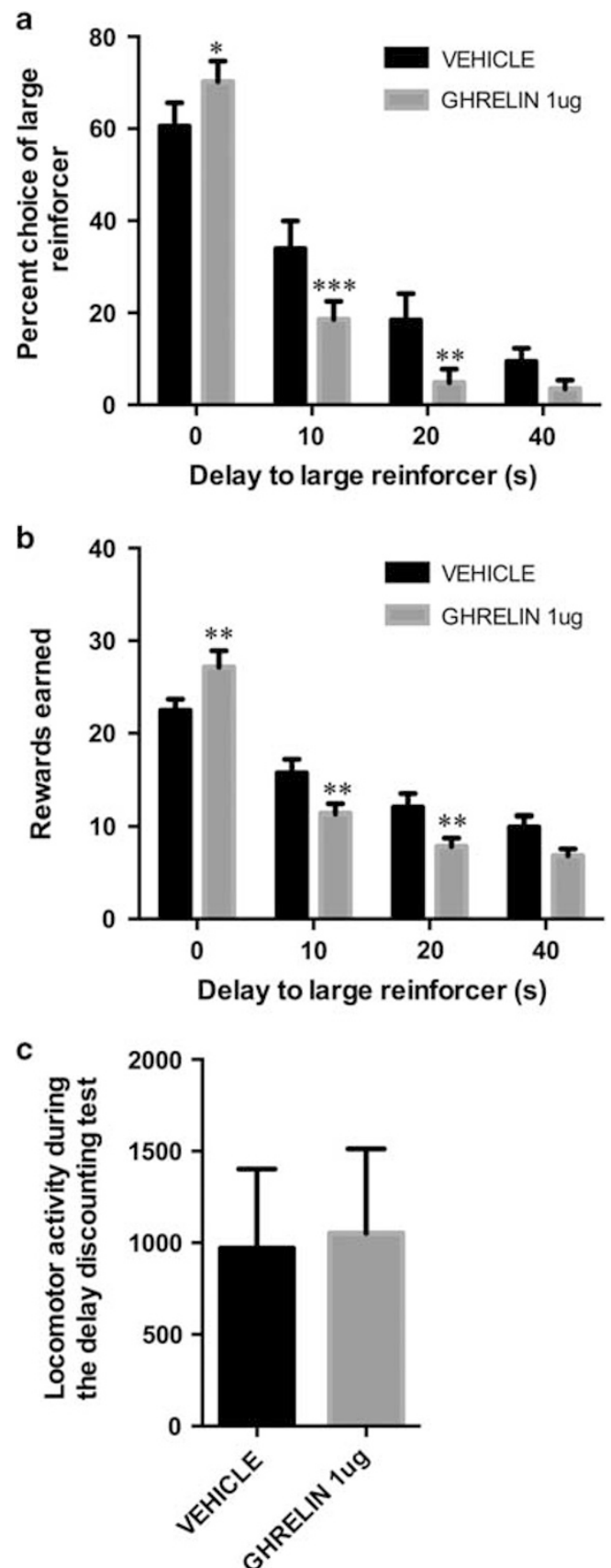

Figure 4 Ghrelin increases impulsive choice measured in the delay discounting task. Ghrelin treatment increased the amount of large rewards obtained when offered with no delay but reduced the amount of large food rewards earned when offered under 10- or 20-s delay (a). The impulsive behavior resulted in a loss of rewards earned during the 10 - and 20-s delays but not when there was no delay imposed on the large rewards (b). No significant changes in locomotor activity were detected after ghrelin treatment during the delay discounting task (c). Data are expressed as mean \pm SEM. $n=25-26$ per each treatment group. $* p<0.05, * * * 0.005$, ***** $p<0.0005$.

presence of the no-go signal. Signaling at the central ghrelin receptor GHSR also had an important role in the increased impulsivity demonstrated after the animals were food restricted, as injection of a GHSR antagonist brought back the efficiency of responding of fasted rats in the DRL to the levels of responding of sated rats. This suggests that endogenous ghrelin, levels of which are high during the initial period of food restriction (Tschop et al, 2000), may have an important role to increase impulsive action during the early stages of fasting.

There are likely multiple neuroanatomical locations from which ghrelin can increase impulsivity. One key area for the control of impulsive behavior is the NAc. Lesions of the NAc, but not of the mPFC, impair impulsive choice (Cardinal et al, 2001). Increased dopamine signaling in the shell of NAc was shown to increase impulsive behavior in a task somewhat similar to the DRL, the 5CSRTT (Cole and Robbins, 1989; Murphy et al, 2008). Activation of D1R in the NAc results in increased impulsive action, whereas blockade of this receptor in the NAc, core, and shell reduces impulsive action (Pattij et al, 2007; Pezze et al, 2007). Importantly, ghrelin's actions on food reward, elicited by GHSR stimulation in the VTA, were previously shown to require intact signaling at the D1R and D2R within the NAc (Skibicka et al, 2013). Thus it is possible that ghrelin may increase dopamine activity in the shell of the NAc by activating GHSRs in the VTA, making the VTA an ideal neural substrate for the direct effect of ghrelin on the DRL responding. Our results support this idea and indicate that direct ghrelin microinjection into the VTA, the only source of dopamine to the NAc, was sufficient to obtain the reduced efficiency seen with whole brain (intra-LV) ghrelin injections. We further show that central ghrelin injection led to a potent increase in dopamine turnover in the NAc without any changes in accumbal dopamine enzyme or receptor expression. These findings are consistent with several previous studies showing that ghrelin activation of the VTA dopamine neurons increases dopamine release in the NAc (Abizaid et al, 2006; Jerlhag et al, 2007; Abizaid, 2009), dopamine production in the VTA, and increased electrical activity of the VTA dopamine neurons (Abizaid et al, 2006).

Abnormal behavioral inhibition has also been associated with dopaminergic signaling in the dorsal striatum. The dorsomedial striatum, in contrast to NAc, was shown to be critical for behavioral inhibition in the stop-signal reaction time test (Eagle and Robbins, 2003). Reduced dorsal striatal (both caudate and putamen) dopamine 2/3 receptor availability, potentially reflecting a compensatory response to increased dopamine release, was positively correlated with increased impulsivity in humans (Lee et al, 2009). Rodent studies indicate an opposing role for dopamine receptors in impulsivity control in this area, with dorsal striatal D1R activation underlying improved behavioral inhibition and D2R contributing to motor disinhibition (Eagle et al, 2011). Although in the current study we did not find any changes in D1R, D2R, or D3R expression after central ghrelin receptor stimulation, we found a clear increase in dopamine turnover in the dorsal striatum after ghrelin injection. Thus it is possible that ghrelin's impact on dorsal striatal dopamine contributes to the increased impulsive action induced by ghrelin. Our finding that links ghrelin with the dorsal striatal dopamine elevation is in line with one other study demonstrating that peripheral ghrelin injection in a mouse model of Parkinson's disease increases dorsal striatal dopamine turnover (Andrews et al, 2009). Ghrelin was also shown to increase the electrical activity of dopamine neurons and dopamine production in the substantia nigra, a major 

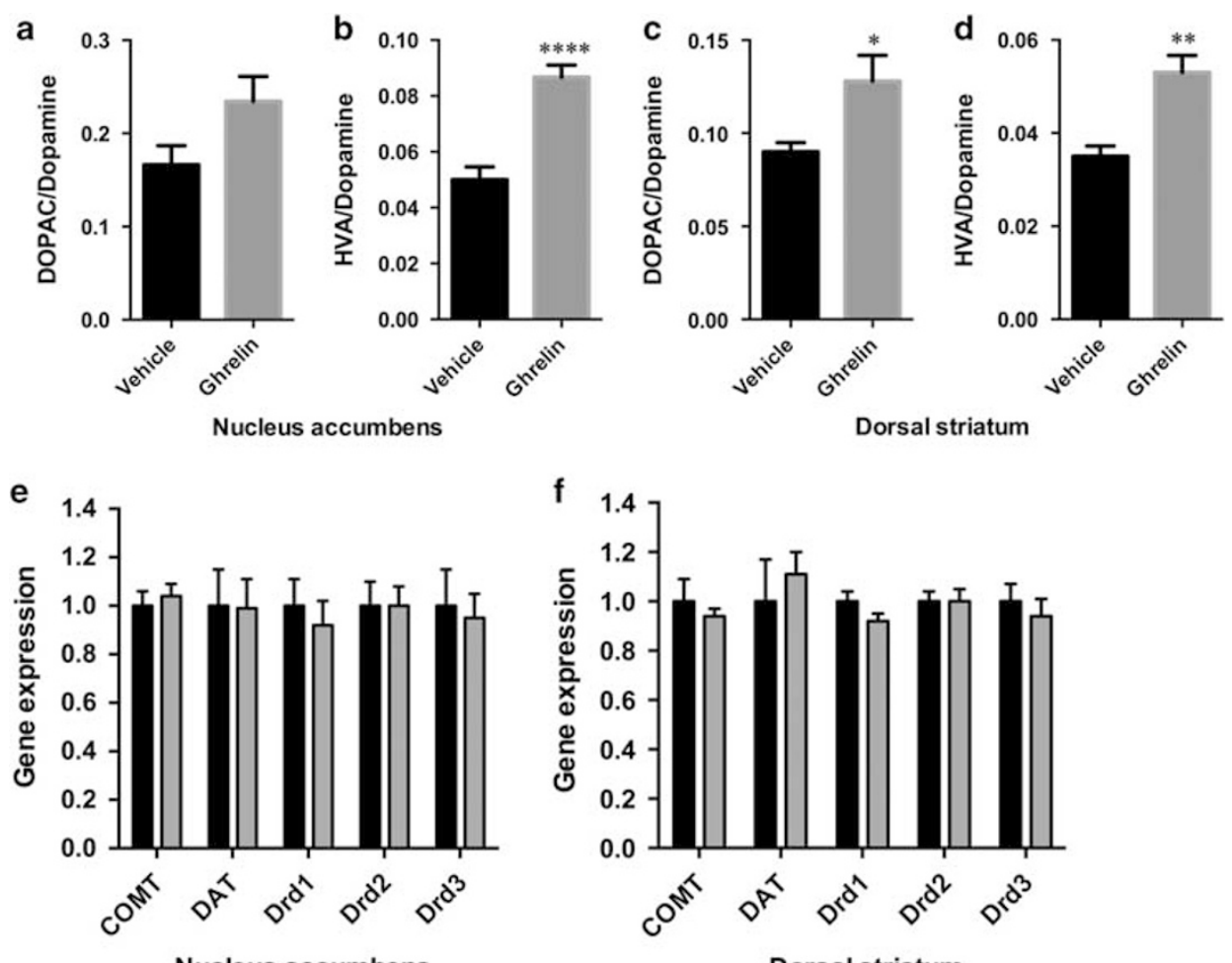

Nucleus accumbens

Dorsal striatum
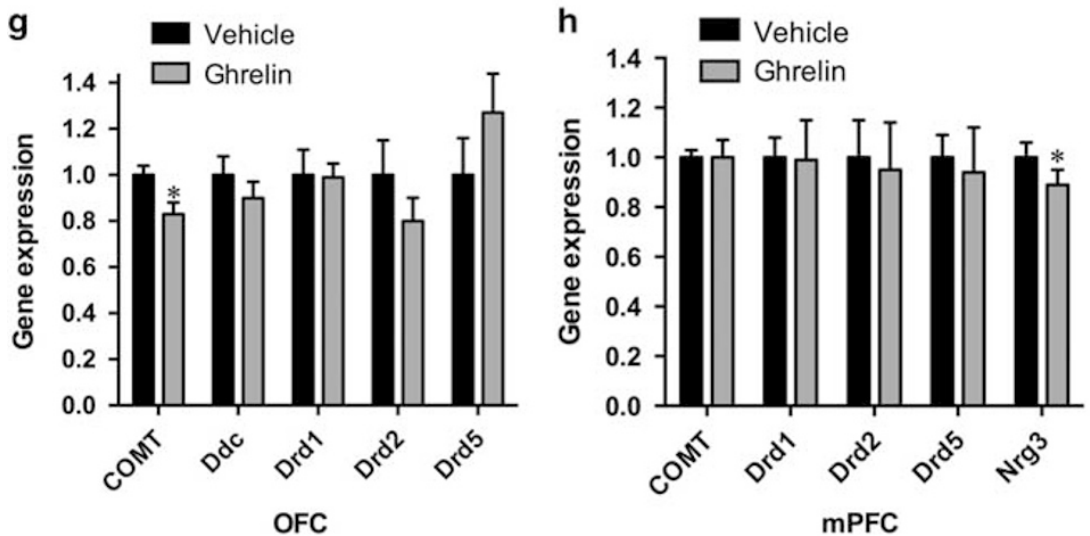

Figure 5 Ghrelin-induced changes in dopamine turnover or dopamine-related genes in the striatum, OFC, and mPFC. Ghrelin increases dopamine turnover in the nucleus accumbens $(\mathrm{a}, \mathrm{b})$ and dorsal striatum $(\mathrm{c}, \mathrm{d})$. Dopamine turnover was determined after lateral ventricle ghrelin or vehicle (aCSF) infusion. Values are expressed as mean \pm SEM. DOPAC, 3,4-dihydroxyphenylacetic acid; HVA, homovanilic acid. $n=9-10$ per group. $* p<0.05$, $* * * 0.005$, $* * * * * 0.00005$. Ghrelin-induced changes in nucleus accumbens (e), dorsal striatum (f), OFC (g), and mPFC (h) gene expression. COMT, catechol-O-methyltransferase; DAT, (Slc6a3) solute carrier family 6 (neurotransmitter transporter, dopamine), member 3; Ddc, dopa decarboxylase (aromatic L-amino acid decarboxylase); DrdI, dopamine receptor DI; Drd2, dopamine receptor D2; Drd3, dopamine receptor D3; Drd5, dopamine receptor D5; and Nrg3, neuregulin-3. Data are expressed as mean \pm SEM. $n=20-24$ per each treatment group. ${ }^{*} p<0.05$.

source of dopamine to the dorsal striatum (Andrews et al, 2009). Together these findings suggest that ghrelin's actions directly in substantia nigra, in addition to the VTA, may also contribute to motor impulsivity disinhibition.

In the final impulsivity test, ghrelin increased impulsive choice by increasing the rat's selection for smaller but immediate rewards instead of the four times larger but delayed food rewards. In contrast to the DRL or the go/no-go test, both of which evaluate the motor impulsivity, the delay discounting test challenges the decision-making capacity of the rat. Ghrelin-treated rats displayed steeper discounting rates compared with their vehicle injection day. The discounting effect was observed particularly at the 10- and 20 -s delays for the large reward, where ghrelin-injected rats were significantly less likely to select the large delayed reward. When the large reward was delivered immediately, however, ghrelin actually increased the choice for the large reward. This is consistent with the well-established role of ghrelin to increase the rewarding value of food (Skibicka and Dickson, 2011; Skibicka et al, 2011b). If a larger reward can be obtained at no extra cost (waiting), then ghrelin biases the selection toward the large reward. If, however, the large 
reward comes with the cost of waiting, our data indicate that ghrelin skews the selection away from the need to wait for the large reward. If ghrelin's impact on this test was based purely on the drive to obtain more food rewards, then an opposite effect to that obtained here would be predicted. Thus, in this test, ghrelin increased the aversion to delays and this aversion overpowered the ghrelin-associated increased value of food rewards. Although it may seem obvious that ghrelin, a hunger hormone, would increase impulsivity/ responding to cues associated with food, in the current experimental setup ghrelin-induced impulsivity results in loss of rewards (in the delay discount and no-go periods of go/no-go) or unnecessary effort without any reward gain. This seems ill-fitting with the role of ghrelin as a hunger hormone, one to assure the maximum amount of nutrition. It allows us, however, to decouple the role of ghrelin as a hunger hormone from an impact of ghrelin on impulsive behavior, thus the increased impulsivity cannot be simply explained by the animal's motivation to obtain more food. Furthermore, the increase in omission rate after ghrelin treatment during the delay discount task argues against a simple explanation of enhanced motivation. Moreover, no change in the total amount of rewards obtained during the entire session after control and ghrelin treatments also argues against the motivational account of the data. Additionally, the reduction in choice of large rewards obtained during the delay discount task was driven by the delays imposed on the high reward, as ghrelin administration to rats undergoing a task identical to delay discount, but without any delays, produced no changes in any of the parameters measured. That satiety was an unlikely explanation for the reduction in obtaining the large and delayed reward is further strengthened by the fact that if no delay was imposed, during the mock version of the delay discount task, the rats were fully capable of eating nearly $100 \%$ more sucrose pellets than compared with the amount consumed during the delay task. Thus both ghrelin- and vehicleinjected rats were quite far from their reward satiation point during the delay task, and ghrelin results obtained during the regular delay discount task are unique to the presence of the delays with large reward delivery.

Ghrelin treatment was associated with a reduced expression of COMT, an enzyme responsible for the bulk of dopamine degradation, in the OFC but not in NAc or dorsal striatum. The OFC has been strongly implicated in impulsivity control. Damage to the OFC in humans is associated with increased impulsive choice, a tendency to choose smaller immediate rewards over larger but delayed rewards (Berlin et al, 2004). A critical role of OFC in impulsivity is highlighted by rat studies showing that lesions of specific regions of the OFC alter impulsivity in the delay discounting test (Mar et al, 2011). This area is suggested to be responsible for computing the final subjective value of different choice options, and activity of neurons in the OFC was shown to be negatively correlated to delay and positively correlated to reward magnitude (Roesch and Olson, 2005). Prefrontal cortex dopamine depletion increases impulsivity (Freund et al, 2014) possibly by increasing D1R in this area, earlier shown to increase impulsive choice (Sonntag et al, 2014). Reduced enzymatic activity of COMT is associated with ADHD and OCD in humans (Cheuk and Wong, 2006; Taylor, 2013), and ADHD patients carrying a variant of this enzyme that is less efficient in metabolizing dopamine show steeper discounting rates compared with those that have a more efficient COMT (Paloyelis et al, 2010). Similar findings have been reported for another enzyme responsible for dopamine degradation in the striatum, DAT (Paloyelis et al, 2010). Furthermore, COMT knockout mice show higher impulsive behavior in the 5CCRT task, with increased premature responding (Papaleo et al, 2012). This is in line with the increased premature responding along with reduced COMT expression shown here after ghrelin stimulation. In the current study, however, we did not detect any changes in DAT in the ventral or dorsal striatum after ghrelin treatment. Using quantitative PCR, we were not able to detect any ghrelin receptors in OFC, eliminating the possibility for any direct action of ghrelin in this area. As ghrelin receptors were previously shown to be present in many brain nuclei sending monosynaptic projections to the OFC, including the VTA (an important source of dopamine to the OFC), an indirect effect of ghrelin seems likely.

The actions of ghrelin on impulsive behavior fit well with the overall behavioral profile associated with increased ghrelin and increased impulsivity. Ghrelin was previously shown to increase food intake, food reward, and novelty seeking (Tschop et al, 2000; Skibicka and Dickson, 2011; Hansson et al, 2012), and impulsivity was shown to be positively correlated with context-dependent food intake, food reward, and novelty seeking (Diergaarde et al, 2009; van den Akker et al, 2013; Velazquez-Sanchez et al, 2014). As all of the aforementioned actions of ghrelin can be elicited by selective activation of ghrelin receptors in the VTA, it is possible that they have a common neural substrate that converges on the VTA dopamine neurons. The contribution of different neuroanatomical regions and neurotransmitters varies with each subtype of impulsivity; therefore, it may be surprising that ghrelin was able to impact on both impulsive choice and action in all of our impulsivity tests. However, this may reflect the broad impact of ghrelin on major neurotransmitter systems such as serotonin and dopamine, as well as neuropeptides previously associated with impulsivity (opioids).

The current manuscript is first to link an endogenous appetite-promoting gut-brain signal ghrelin to impulsive behavior in rodents. The therapeutic implications of our discovery are considerable, especially considering that few substances currently available on the market have an ability to target all forms of impulsive responding. Interest in ghrelin (GHSR) antagonists is already growing owing to the potential antiobesity and antialcohol overconsumption effects of GHSR blockade; our current data expand this interest into the field of maladaptive impulsivity.

\section{FUNDING AND DISCLOSURE}

This research was funded by the Swedish Research Council (2014-2945), Novo Nordisk Foundation Excellence project grant, Ragnar Söderberg Foundation, Harald Jeanssons Stiftelse and Greta Jeanssons Stiftelse, and Magnus Bergvalls Stiftelse (all to KPS). SLD was funded by EC 7th Framework grants Nudge.it (607310), Full4Health (266408), and NeuroFAST (245009) and by Avtal om Läkarutbildning och Forskning (ALFBGB-138741). The authors declare no conflict of interest. 


\section{ACKNOWLEDGMENTS}

We thank the Genomics Core Facility platform at the Sahlgrenska Academy, University of Gothenburg for the use of their equipment.

\section{REFERENCES}

Abizaid A (2009). Ghrelin and dopamine: new insights on the peripheral regulation of appetite. J Neuroendocrinol 21: 787-793. Abizaid A, Liu ZW, Andrews ZB, Shanabrough M, Borok E, Elsworth JD et al (2006). Ghrelin modulates the activity and synaptic input organization of midbrain dopamine neurons while promoting appetite. J Clin Invest 116: 3229-3239.

Anderberg RH, Anefors C, Bergquist F, Nissbrandt H, Skibicka KP (2014). Dopamine signaling in the amygdala, increased by food ingestion and GLP-1, regulates feeding behavior. Physiol Behav 136: $135-144$

Andrews ZB, Erion D, Beiler R, Liu ZW, Abizaid A, Zigman J et al (2009). Ghrelin promotes and protects nigrostriatal dopamine function via a UCP2-dependent mitochondrial mechanism. J Neurosci 29: 14057-14065.

Bari A, Robbins TW (2013). Inhibition and impulsivity: behavioral and neural basis of response control. Progr Neurobiol 108: 44-79.

Berlin HA, Rolls ET, Kischka U (2004). Impulsivity, time perception, emotion and reinforcement sensitivity in patients with orbitofrontal cortex lesions. Brain 127: 1108-1126.

Bizot J, Le Bihan C, Puech AJ, Hamon M, Thiebot M (1999). Serotonin and tolerance to delay of reward in rats. Psychopharmacology 146: 400-412.

Cardinal RN, Pennicott DR, Sugathapala CL, Robbins TW, Everitt BJ (2001). Impulsive choice induced in rats by lesions of the nucleus accumbens core. Science 292: 2499-2501.

Cheuk DK, Wong V (2006). Meta-analysis of association between a catechol-O-methyltransferase gene polymorphism and attention deficit hyperactivity disorder. Behav Genet 36: 651-659.

Cole BJ, Robbins TW (1989). Effects of 6-hydroxydopamine lesions of the nucleus accumbens septi on performance of a 5-choice serial reaction time task in rats: implications for theories of selective attention and arousal. Behav Brain Res 33: 165-179.

Cummings DE, Frayo RS, Marmonier C, Aubert R, Chapelot D (2004). Plasma ghrelin levels and hunger scores in humans initiating meals voluntarily without time- and food-related cues. Am J Physiol Endocrinol Metab 287: E297-E304.

Dawe S, Loxton NJ (2004). The role of impulsivity in the development of substance use and eating disorders. Neurosci Biobehav Rev 28: 343-351.

Diergaarde L, Pattij T, Nawijn L, Schoffelmeer AN, De Vries TJ (2009). Trait impulsivity predicts escalation of sucrose seeking and hypersensitivity to sucrose-associated stimuli. Behav Neurosci 123: 794-803.

Eagle DM, Lehmann O, Theobald DE, Pena Y, Zakaria R, Ghosh R et al (2009). Serotonin depletion impairs waiting but not stopsignal reaction time in rats: implications for theories of the role of 5-HT in behavioral inhibition. Neuropsychopharmacology 34: 1311-1321.

Eagle DM, Robbins TW (2003). Inhibitory control in rats performing a stop-signal reaction-time task: effects of lesions of the medial striatum and d-amphetamine. Behav Neurosci 117: 1302-1317.

Eagle DM, Wong JC, Allan ME, Mar AC, Theobald DE, Robbins TW (2011). Contrasting roles for dopamine D1 and D2 receptor subtypes in the dorsomedial striatum but not the nucleus accumbens core during behavioral inhibition in the stopsignal task in rats. J Neurosci 31: 7349-7356.

Freund N, MacGillivilray HT, Thompson BS, Lukkes JL, Stanis JJ, Brenhouse HC et al (2014). Sex-dependent changes in ADHD- like behaviors in juvenile rats following cortical dopamine depletion. Behav Brain Res 270: 357-363.

Hansson C, Alvarez-Crespo M, Taube M, Skibicka KP, Schmidt L, Karlsson-Lindahl L et al (2014). Influence of ghrelin on the central serotonergic signaling system in mice. Neuropharmacology 79: 498-505.

Hansson C, Shirazi RH, Naslund J, Vogel H, Neuber C, Holm G et al (2012). Ghrelin influences novelty seeking behavior in rodents and men. PLoS One 7: e50409.

Harrison AA, Everitt BJ, Robbins TW (1997). Central 5-HT depletion enhances impulsive responding without affecting the accuracy of attentional performance: interactions with dopaminergic mechanisms. Psychopharmacology 133: 329-342.

Jerlhag E, Egecioglu E, Dickson SL, Douhan A, Svensson L, Engel JA (2007). Ghrelin administration into tegmental areas stimulates locomotor activity and increases extracellular concentration of dopamine in the nucleus accumbens. Addict Biol 12: 6-16.

Jerlhag E, Egecioglu E, Landgren S, Salome N, Heilig M, Moechars D et al (2009). Requirement of central ghrelin signaling for alcohol reward. Proc Natl Acad Sci USA 106: 11318-11323.

Jupp B, Caprioli D, Dalley JW (2013). Highly impulsive rats: modelling an endophenotype to determine the neurobiological, genetic and environmental mechanisms of addiction. Dis Models Mechanisms 6: 302-311.

Lee B, London ED, Poldrack RA, Farahi J, Nacca A, Monterosso JR et al (2009). Striatal dopamine $\mathrm{d} 2 / \mathrm{d} 3$ receptor availability is reduced in methamphetamine dependence and is linked to impulsivity. J Neurosci 29: 14734-14740.

Livak KJ, Schmittgen TD (2001). Analysis of relative gene expression data using real-time quantitative PCR and the 2 (-Delta Delta C(T)) Method. Methods 25: 402-408.

Loos M, Mueller T, Gouwenberg Y, Wijnands R, van der Loo RJ, Neuro-BSIK Mouse Phenomics Consortium et al (2014). Neuregulin-3 in the mouse medial prefrontal cortex regulates impulsive action. Biol Psychiatry 76: 648-655.

Mangabeira V, Garcia-Mijares M, Silva MT (2015). Sugar withdrawal and differential reinforcement of low rate (DRL) performance in rats. Physiol Behav 139: 468-473.

Mar AC, Robbins TW (2007). Delay discounting and impulsive choice in the rat. Curr Protoc Neurosci Chapter 8(Unit 8): 22.

Mar AC, Walker AL, Theobald DE, Eagle DM, Robbins TW (2011). Dissociable effects of lesions to orbitofrontal cortex subregions on impulsive choice in the rat. J Neurosci 31: 6398-6404.

Masaki D, Yokoyama C, Kinoshita S, Tsuchida H, Nakatomi Y, Yoshimoto $\mathrm{K}$ et al (2006). Relationship between limbic and cortical 5-HT neurotransmission and acquisition and reversal learning in a go/no-go task in rats. Psychopharmacology 189: 249-258.

Menzies JR, Skibicka KP, Leng G, Dickson SL (2013). Ghrelin, reward and motivation. Endocr Dev 25: 101-111.

Miyazaki KW, Miyazaki K, Doya K (2012). Activation of dorsal raphe serotonin neurons is necessary for waiting for delayed rewards. J Neurosci 32: 10451-10457.

Miyazaki KW, Miyazaki K, Tanaka KF, Yamanaka A, Takahashi A, Tabuchi S et al (2014). Optogenetic activation of dorsal raphe serotonin neurons enhances patience for future rewards. Curr Biol 24: 2033-2040.

Moulin A, Demange L, Berge G, Gagne D, Ryan J, Mousseaux D et al (2007). Toward potent ghrelin receptor ligands based on trisubstituted 1,2,4-triazole structure. 2. Synthesis and pharmacological in vitro and in vivo evaluations. I Med Chem 50: 5790-5806.

Murphy ER, Robinson ES, Theobald DE, Dalley JW, Robbins TW (2008). Contrasting effects of selective lesions of nucleus accumbens core or shell on inhibitory control and amphetamine-induced impulsive behaviour. Eur J Neurosci 28: 353-363. 
Paloyelis Y, Asherson P, Mehta MA, Faraone SV, Kuntsi J (2010). DAT1 and COMT effects on delay discounting and trait impulsivity in male adolescents with attention deficit/hyperactivity disorder and healthy controls. Neuropsychopharmacology 35: 2414-2426.

Papaleo F, Erickson L, Liu G, Chen J, Weinberger DR (2012). Effects of sex and COMT genotype on environmentally modulated cognitive control in mice. Proc Natl Acad Sci USA 109: 20160-20165.

Pattij T, Janssen MC, Vanderschuren LJ, Schoffelmeer AN, van Gaalen MM (2007). Involvement of dopamine D1 and D2 receptors in the nucleus accumbens core and shell in inhibitory response control. Psychopharmacology 191: 587-598.

Peterson JD, Wolf ME, White FJ (2003). Impaired DRL 30 performance during amphetamine withdrawal. Behav Brain Res 143: $101-108$

Pezze MA, Dalley JW, Robbins TW (2007). Differential roles of dopamine D1 and D2 receptors in the nucleus accumbens in attentional performance on the five-choice serial reaction time task. Neuropsychopharmacology 32: 273-283.

Roesch MR, Olson CR (2005). Neuronal activity in primate orbitofrontal cortex reflects the value of time. J Neurophysiol 94: 2457-2471.

Schag K, Schonleber J, Teufel M, Zipfel S, Giel KE (2013). Foodrelated impulsivity in obesity and binge eating disorder-a systematic review. Obes Rev 14: 477-495.

Skibicka KP, Dickson SL (2011). Ghrelin and food reward: the story of potential underlying substrates. Peptides 32: 2265-2273.

Skibicka KP, Hansson C, Alvarez-Crespo M, Friberg PA, Dickson SL (2011a). Ghrelin directly targets the ventral tegmental area to increase food motivation. Neuroscience 180: 129-137.

Skibicka KP, Hansson C, Egecioglu E, Dickson SL (2011b). Role of ghrelin in food reward: impact of ghrelin on sucrose selfadministration and mesolimbic dopamine and acetylcholine receptor gene expression. Addict Biol 17: 95-107.
Skibicka KP, Shirazi RH, Hansson C, Dickson SL (2012). Ghrelin interacts with neuropeptide Y Y1 and opioid receptors to increase food reward. Endocrinology 153: 1194-1205.

Skibicka KP, Shirazi RH, Rabasa-Papio C, Alvarez-Crespo M, Neuber C, Vogel H et al (2013). Divergent circuitry underlying food reward and intake effects of ghrelin: Dopaminergic VTA-accumbens projection mediates ghrelin's effect on food reward but not food intake. Neuropharmacology 73C: 274-283.

Sonntag KC, Brenhouse HC, Freund N, Thompson BS, Puhl M, Andersen SL (2014). Viral over-expression of D1 dopamine receptors in the prefrontal cortex increase high-risk behaviors in adults: comparison with adolescents. Psychopharmacology 231: $1615-1626$.

Taylor S (2013). Molecular genetics of obsessive-compulsive disorder: a comprehensive meta-analysis of genetic association studies. Mol Psychiatry 18: 799-805.

Tschop M, Smiley DL, Heiman ML (2000). Ghrelin induces adiposity in rodents. Nature 407: 908-913.

van den Akker K, Jansen A, Frentz F, Havermans RC (2013). Impulsivity makes more susceptible to overeating after contextual appetitive conditioning. Appetite 70: 73-80.

Velazquez-Sanchez C, Ferragud A, Moore CF, Everitt BJ, Sabino V, Cottone P (2014). High trait impulsivity predicts food addiction-like behavior in the rat. Neuropsychopharmacology 39: 2463-2472.

(c) $(\&)$ This work is licensed under a Creative Commons Attribution-NonCommercial-NoDerivs $\quad 4.0$ International License. The images or other third party material in this article are included in the article's Creative Commons license, unless indicated otherwise in the credit line; if the material is not included under the Creative Commons license, users will need to obtain permission from the license holder to reproduce the material. To view a copy of this license, visit http://creativecommons.org/licenses/by-nc-nd/4.0/

Supplementary Information accompanies the paper on the Neuropsychopharmacology website (http://www.nature.com/npp) 